\title{
INFLUENCE OF THE PERSONAL POTENTIAL ON ADAPTATION OF YOUNG ENGINEERS IN THE SPHERE OF THE INDUSTRIAL PRODUCTION
}

\author{
Liubov Kotlyarova \\ National Research Nuclear University, Russia \\ Ekaterina Sysoeva \\ National Research Nuclear University, Russia
}

\begin{abstract}
The article analyzes the results of the experimental research of the young engineers' peculiarities at the first job placement at the industrial plants. The participants of the research were tested while being graduates and then again as young specialists. In the researched sampling we have pointed out the groups with different degree of "adaptation" to the working activities factor: $36 \%$ with high level of adaptation, $31 \%$ with medium, and 33 $\%$ with low adaptation. It is proved that $13 \%$ of the young specialists resign within the first months after the job placement in spite of the favourable conditions for the working activities. We have found out the reasons for resignation while interviewing the respondents. The survey of the successfully adapted young specialists has allowed to point out the factors that favourably influence the completion of the adaptation processes.

Basing on the results of the tests aimed at the definition of the personal potential peculiarities, we have compiled characteristics for each group. We have demonstrated the influence of the students' adaptation potential formed by the graduation on the effectiveness of the professional adaptation.
\end{abstract}

Keywords: adaptation, deadaptation, personal potential, young engineers.

\section{Introduction}

Effectiveness of the plants activities according to the leading specialists in the area of organizing industrial production is defined by different competitive factors diversity of which can be narrowed to two main ones: technology and resources (Antonov et al., 2012; Turovets \& Buchalkov, 2011). To achieve success and keep the leading positions on the production market one needs to always increase the effectiveness of the given factors. Multiple research of the recent years has proved that the development of the organizational resource and improvement of the methods is possible only when qualified specialists take part in the process. The human resources have started playing the major role in the stable activities of a plant (Armstrong, 2012; Kochan \& Dyer, 1993; Maksimtsev, 2015). 
Industrial corporations when working out strategic plans for development now pay more attention to the recruitment policy. The priority tasks are considered the ones on attracting young, promising specialists. Such ones who are oriented to continual working interaction and who plan to connect with the industry their professional formation and development.

We have conducted the analysis of different informational sources (scientific literature, annual reports on the activity of the country industrial plants, informational sources of the significant for the industry reports on personnel management and speeches of different head managers of plants). The analysis allows us to conclude that the inflow of the young specialists does not meet the demands of the plants (Kotlyarova \& Zhutikov, 2013). That is why the personnel managers have to use in their work professional-oriented technologies aimed not only at attraction of the personnel but also at staff securing and development in the organization.

Universities and colleges are particularly interested in usage of the technologies of this kind because the graduates' effective job placement is one of the criteria of educational institution competitiveness.

In the context of the mentioned above it should be noted that the HR services of the industrial plants and university Centres for career and competences development have common tasks aimed at development and usage of the effective professional-oriented technologies.

Research on the personnel management has been conducted for many years in the native labour psychology school. Different psychological methods have been developed and they have proved their high effectiveness in working with staff (Maklakov, 2008; Nikiforov, 2010). However, in 2012 extensive certification of the working places started in our country. It is still being conducted as it is required by the introduction of the professional standards. The certification presents new requirements to the personnel management technologies including attraction of students' attention to the choice of the priority plant for the job placement, creation of the organizational conditions and young specialists' adaptation. To develop such technologies people need psychological knowledge on modern graduates' readiness to professional activities, their personal, adaptation potential; behavioural strategies in the process of choosing a company for the job placement.

\section{Objectives, method, participants, instruments and procedures.}

The objective of the conducted research was the study of the peculiarities of the personal potential (as an integral characteristic including personal peculiarities and behavioural strategies) of the young specialists who have successfully adapted to the activities and those having resigned within the first 
year from the job placement at the industrial plant.

To reach the set goal we needed to solve the following tasks: to define peculiarities of the young specialists' adaptation and single out in the sampling groups with different indices (high, medium, low) according to the given factor; - define the personal potential peculiarities in groups with different adaptation indices; - uncover of the reasons for the resignation; - identify the behavioural strategies peculiarities and adaptation mechanisms.

In the given research we based upon the theoretical concepts on adaptation and personal potential introduced by the native authors - A.G. Maklakov (2008), G.S. Nikiforova (2010), V.P. Rostovsky (2010), D.A. Leontiev (2011), V.A. Tolochek (2015) etc.

The research has been conducted from 2013 to 2015. 286 people voluntarily took part in it. At first as the graduate students of a technical university, then as young specialists with whom we have had contacts for a year after the job placement. The respondents' age varied from 21 to 25 years. The selection contained $73 \%$ males and $27 \%$ females. We used simple randomized selection while forming the pool for sampling.

The participants of the research, depending on the context of the stated material, will be called: students, subjects (those who have been tested), respondents (have been interviewed), adaptants (the given notion is used for the employees who have their first job placement, during the probation period), young specialists (organization employees having the given status due to the legal norms).

The students have been tested in the assessment centre of the socialpsychological service. This has allowed creation of psychological personal profiles the integral parts of which were qualities of different levels. The respondents' interview in the status of young specialists has been conducted twice: in the first 3 months after the job placement and at the end of the first year.

The research was based on comparative-longitude, systematic and personal-oriented approaches.

The data received in the research had been tested mathematic-statistically. We used cluster, factor and comparative analyses. When collecting the data, we used traditional approaches and programmes Psychometric Expert 6, SurveyMonkey.

The theoretical aspects on which the given research is based have been presented in details in our earlier works. (Rostovsky \& Kotlyarova, 2010).

In the given article we consider appropriate to give only a short definition to the notions "adaptation" and its constituents: "adaptation potential", "adaptivity", "adaptedness". We will stick to these terms throughout the research. 
In the available scientific literature adaptation is described as a permanent process of person's active coordination of his/her personal peculiarities with the environmental conditions (requirements of the working conditions, partners' peculiarities, social groups, organizational structure etc.), providing success for his/her professional activities and full personal self-realization in all the spheres of the life-activities (Tolochek, 2015). Person's adaptation to labour is the aggregate of the psychological mechanisms becoming apparent in success of the professional activities, satisfaction with the labour, optimal psychological and professional "price" for the result, coordination with the norms of the activities, group norms, requirements of the organizational culture, interaction with the partners manifesting themselves as optimal professional career. In general adaptation reflects the quality of the coordination of the inner and outer conditions of a subject and his/her full self-realization in different spheres of life.

The term "deadaptation" in the Russian literature is used to define the violations of the person's interaction with the environment. The notion of the deadaptation is defined differently depending on the emphasis on the features of the adaptation process.

Deadaptation is manifested in different activities disorders, for example, in: decrease of the labour productivity and its quality, violation of the labour discipline, increase of the accidence and trauma rate; refusal from the activities. The forms of the refusal can be different: cease to fulfill professional activities, inactivity while an accident is occurring, resignation, social protest etc. Nalchadzhyan (1988, p. 23). emphasizes: "Deadaptive can be such a course of inner-psychological processes and behavior that leads not to solving of the problematic situation but to its aggravation, to intensification of the difficulties and other unpleasant experiences that it causes".

In the Russian literature a lot of authors see the notion "adaptation potential" as a synonym to the notion "adaptivity" and it is used to define the characteristic that shows personality's resources towards the psychological adaptation in different spheres of life and activities (professional, family, communicative, informational etc.). Person's adaptation to the environment, different types and conditions of activities require different combinations of the intensity of these or those adaptive qualities of a personality. These qualities are defined as personality's individual psychologic peculiarities.

One of the leading country specialists in the area of the labour psychology Maklakov (2001) while studying the role of the personal adaptation potential notices “individual adaptive abilities greatly depend on personality's psychological features, defining the opportunity of the adequate regulation of the body's functional state in different conditions of life and activities. The more substantial the adaptive abilities are, the higher is the probability of the normal 
body functioning and of effective activities while the intensity of the influence of the psychogenic factors of the environment is increasing". Evaluation of personality's adaptation abilities can be possible via the evaluation of the development of the psychological characteristics, that are crucially important for the regulation of the psychological activity and the process of adaptation. The higher the level of these characteristics development is, the higher the probability of the successful adaptation is, the more diverse are the environmental factors to which the individual can adjust to. The given psychological peculiarities of a personality are interconnected and are one of the integral characteristics of a person's psychological development - personal adaptation potential (PAP further on we will use this abbreviation). The PAP index contains information on individual's characteristics correlation or discrepancies to the demands of the environment. It also allows differentiating people according to degree of stability under the influence of the psycho emotional stressors. Consequently, it gives a chance with a certain degree of success to solve the problems of forecasting person's activities effectiveness in the extreme conditions.

Maklakov (2001) picks out as one of the main psychological constituents of the personal adaptation potential: nervous-psychological stability; moral standardization; level of the social adaptivity; communicative abilities. To evaluate the following characteristics Maklakov (2008) has worked out the "Multi-level personal inventory" - "Adaptivity" that is used by many specialists in the system of the professional selection.

According to Leontiev (2007) personal potential is a stable aggregate of the personal features accumulated by a person in the process of life and defining his/her ability to the optimal performance of activities. As the integral characteristics of the adaptivity the author of the given concept singles out the following features: personality's system of beliefs about the world, of $\mathrm{him} /$ herself and relationships with the world; self-evaluation of the personality that is the core of the self-regulation and defines the degree of perception adequacy of the conditions of activities and personal abilities; feeling of the social support, determines the feeling of the self-significance; the intensity of the conflict proneness; experience of the social communication (Leontiev \& Rasskazova, 2006).

In works by Rostovsky (2010) personality's adaptation potential is understood as an integral characteristic that includes stable aggregate of the individual-psychological and personal features, defining the effectiveness of the adaptation in different spheres of life and activities.

By "adaptedness" many researchers understand the result of the adaptation. Jung (2003) was considering the most important in adaptation the intensity of the organism's adjustment to the environment, and also the possibilities that it 
has in order to support functioning at the necessary level - that is the so-called adaptedness.

In the native researchers works personality's adaptivity at the psychological level is defined as the "condition of the organism's adaptive systems reached as a result of the active adaptation to the...psychic situations" (Vorobiev, 1996, p. 91). According to Vorobiev (1996) personality's deadaptation is personality's structure with all the discrepancies and deregulations of some sub-systems that are the consequences of the unsuccessful adaptation.

In the work by Onoshko (2009) social-psychological adaptedness is defined as such a condition of relationships between a personality and group, when a personality without the outer and inner expressed conflicts productively fulfills its leading activity, satisfies his/her main sociogenic demands, correlates with the role expectations that the group presents to it, self-affirms adequately and freely expresses its creative abilities.

Summarizing the studied works, we can conclude that adaptedness by many authors is understood as a psychological condition reached as a result of realization of the personal adaptation potential.

To define the degree of young specialists' adaptedness to the professional activities at a plant we used the inventory "Evaluation of the work satisfaction" (Raigorodsky, 2009). It consists of 14 statements, evaluated according to the 5 points scale (the points range from 14 to 70 points). According to the author's concept after the survey we can single out three groups in the sampling - with high (50 to 70 points), medium (30-50 points) and low (up to 30 points) indices according to the factor "work satisfaction". The authors of the technique believe that while interviewing young specialists in the adaptation period the degree of the job satisfaction can be considered an adaptedness criterion. That is why in our research to define the differences between the respondents on the intensity of adaptation we have used the given technique.

The inventory "Young specialists' opinion on activities and relationships in the organization" has been created by us and includes 120 questions. It can be used in the form of a survey or an interview. The inventory allows to point out young employees' opinion on the reasons for resignation and also on the positive and destructive influence on the processes of the professional adaptation/deadaptation psychological, organizational, ergonomical, socialeconomical factors such as (health; job satisfaction; relationships with the boss, instructor and the colleagues; working area; information streams dealing with the content of the activities and exact working tasks; working schedule; working time management; satisfaction with the payment and benefits; attitude to the motivational programmes; organizational culture; conditions for the development of the professional competences and the personal potential; etc.) 
The respondents' survey with the use of the personal techniques has been conducted in the period before the graduation from the university.

To define personal peculiarities we have used the 16 personality factor questionnaire by Cattell (16 PF) form $\mathrm{A}$. The questionnaire is aimed at evaluating 20 personality factors (16 of the of the high range and 4 of low range) and gives many-sided information on the personal features that are called constitutional factors (Leonov, 2013). Every personal trait is bipolar that is why every has got the name characterizing the degree of development. The unit of calculation is sten in the range from 0 to 10 , low range is from 0 to 3 , high ranges - more than 7 stens.

To define the measures of the person's ability to cope with the stressful situation keeping inner balance without lowering effectiveness of the activities, we have used the methods by Leontiev "The viability test" (Leontiev \& Rasskazova, 2006). Viability is considered by the authors of the inventory as the self-image personality's system on itself, the world, on relationships with the world. Leontiev, defining the viability, writes, "This disposition includes three relatively autonomous components: involvement, control and risk acceptance. Intensity of these components in the viability in general prevent from occurrence of the inner tension in the stressful situations due to hardy coping with the stresses and perception of them as less significant" (Leontiev \& Rasskazova, 2006, p. 5). The given inventory represents the modified and adapted survey by Salvatore Maddi - "Hardiness Survey" for the use in the Russian-speaking environment. The scales for the test are viability (integral characteristic, the medium range $-80.71+-18.53$ ) and its constituents - involvement (medium $37.64+-8.08$ ), control $29.17+-8.43$, risk acceptance $13.91+-4.39$ ). The survey was conducted before the students' graduation from the university.

Personal adaptation potential (PAP) was defined with the help of the Maklakov, Chermyanin's "Multi-level personal inventory - Adaptivity" (author's abbreviation - "'MLPI-A) (Encyclopedia of the Psycho-Diagnosis, 2009) and Rostovsky's - "Adaptation potential" and "Adaptation Mechanisms" (Rostovsky \& Kotlyarova, 2010).

The inventory by Maklakov, Chermyanin "MPLI-A" includes 165 questions with "yes" and "no" answers. The constituents of the personal adaptation potential are the scales: authenticity (A), range from 0 to 13; adaptive abilities (AA), range 0 to 153 points; neuro-psychological stability (NPS), range 0 to 95 ; communicative peculiarities $(\mathrm{CP})$, range 0 to 31 points; moral standardization (MS), range 0 to 24 points.

The Rostovsky inventory "Adaptation potential" allows to identify 24 parameters touching upon different spheres of the adaptation to: the "I" outer image, the "I" inner image, communication with teachers and administration; the system of the personal relations with the groupmates; in studies; in the 
higher school area; adaptation in the family; the social everyday conditions; in the past, present, future; energetic adaptation; informational; adaptation; adaptation to the working schedule and so on.

The inventory by Rostovsky "Adaptation Mechanisms" allows to point out adaptation mechanisms, "aimed at preservation and improvement of the psychological processes, conditions and peculiarities of a personality in order to perceive and realize his/her personality in its essence: preservation of the wholeness and integrity of the structure, activities, self-actualization, selfexpression etc. If the personality is incapable of optimal adaptation to different life situations then the mechanisms of the psychological protection come into action - these are the psychological processes providing compensation of the negative deviation in the adaptation processes and weakening neuropsychological tension" (Rostovsky \& Kotlyarova, 2010. p. 30). The use of the questionnaire allowed pointing out the following adaptation mechanisms: domination, submission, compromise, leaving, rejection, conflict, forming of the barriers, economy of the personal resources, accumulation of the personal potential, approaching, over-compensation, comparison, aggression, false activeness, addressing for help, dependency, anxiety, self-destruction, substituting aim, leaving for the unreal world, rationalization, complication, simplification, search for the substituting aim.

\section{Results of research}

According to the factor "adaptedness" to the professional activities reflecting the result of the adaptation process, its success-failure we have singled out 3 groups. The first group comprising $36 \%$ ( $\mathrm{N}=103$ persons) out of the sampling includes respondents having scored high points on the factor. In the second group (31\% of the sampling, 89 people) were included the respondents with the medium indices according to the "adaptedness factor". The third group consists of (33\% of the sampling, 92 persons) was built by two sub-groups. The first - young specialists who resigned within the first year after the first job placement (13\%, 36 people) and the second who have been transferred to other working positions inside the plant $(20 \%, 56$ people) within the first year.

In accordance with the objective of the given research let us consider the peculiarities of the adaptation potential in the polar groups - with the highest (the first group) and the lowest (sub-group of the third group that included those who have resigned) indices according to the factor "adaptedness". The data received in the group with the medium indices will be introduces in a different work.

The analysis of the survey results and respondents' interviews in the first group (with the highest adaptation indices) has indicated that all the young 
specialists have been working at the plant for a year, have been happy with their status in the organization and the results of their activities, have been planning their personal development within the plant, have positively evaluated the organization of the activities and organizational culture at the plant, positively estimated relationships with the colleagues and communication. The respondents of the given group have indicated that to their professional adaptation contributed: exact understanding of the contents and character of the activities and job requirements and the purpose on their fulfilling, positive perception of the organization culture, abilities to have non-conflict relationships with the colleagues and supervisors, good organization of the working area.

To the least important factors influencing the success of the adaptation belong economical factors of the material stimulation, to be more exact - salary and extra-payments. Summarizing the received data, we can conclude that the reasons for the successful initial professional adaptation of the young specialists, according to their own ideas belong: developed personal resources, precisely informational, motivational and communicative components and the organizational culture.

Analysis of the survey and interview results in the group with the low indices of the "adaptedness" factors allowed pointing out the following peculiarities. First of all, we should pay attention to the fact that all the respondents of the given group (during the survey and the interview) have mentioned their low satisfaction with the activities and their social-role status in the organization. Among the most crucial reasons influencing the decision on resigning the respondents mention (in the rank order): discrepancy between the expectations and the reality of work; working schedule; organization of the working area; dissatisfaction with the set communication system; insufficiency of attention from the boss to young specialists' demands and requirements; unclear set of working tasks from the supervisors. The personal and organizational factors were among the reasons for resignation. The least influential on making the resignation decision, according to the respondents were the economical factors.

Summarizing the found out patterns we should note that according to the young specialists' opinion, the adaptation/deadaptation is greatly influenced by the level of the personal resources formation and is slightly influenced by the economical factors. The influence of the organizational and social factors is estimated as moderate but not decisive. Weak influence on adaptation/deadaptation of the economical factors (pointed out in all of the groups) we can explain by the fact that, most of the respondents were employed at the plants having the leading positions in the industry area and consequently with high economical indices. That was reflected in the system of the workers' 
Liubov Kotlyarova, Ekaterina Sysoeva. Influence of the Personal Potential on Adaptation of Young Engineers in the Sphere of the Industrial Production

material stimulation on the whole.

Let us examine the results received while comparing personal profiles compiled in polar groups pointed out according to the "adaptedness" factor.

At first we will examine personal profiles (table 1) compiled on the basis of R. Cattell "16 Personality Factor Inventory" (16 PF).

Table 1 Personal adaptation profiles in the groups with different adaptedness indices

\begin{tabular}{|l|c|c|}
\hline \multirow{2}{*}{$\begin{array}{l}\text { R. Cattel's inventory factors defining } \\
\text { personal peculiarities }\end{array}$} & \multicolumn{2}{|c|}{ Mean profile in groups } \\
\cline { 2 - 3 } & $\begin{array}{l}\text { With high indices of } \\
\text { adaptedness (stens) }\end{array}$ & $\begin{array}{c}\text { With low indicess of } \\
\text { adaptedness (stens) }\end{array}$ \\
\hline A: Warm+/reserved- & $5.5 \pm 0.71$ & $6.6+0.65$ \\
\hline B: Mental capacity: high+, low- & $7.0 \pm 0,53$ & $6.1 \pm 0.90$ \\
\hline C: Emotionally stable+/reactive- & $6.3 \pm 0.70$ & $3.4 \pm 0,31^{*}$ \\
\hline E: Dominant+/deferential- & $6.5 \pm 0.24$ & $5,2 \pm 0.50$ \\
\hline F: lively+/serious- & $5.3+0.33$ & $6,3 \pm 0.40$ \\
\hline G: Rule conscious+/expedient- & $7.0 \pm 0.80$ & $4.20+0.20^{*}$ \\
\hline H: Bold+/shy- & $5,3 \pm 0.71$ & $6.8+0.5$ \\
\hline I: Sensitive+/unsentimental- & $5,6 \pm 0 / 4$ & $3.5+0 / 6$ \\
\hline L: Vigilant+/trusting- & $5,7 \pm 0.28$ & $6.3+0.56$ \\
\hline M: Abstracted+/practical- & $4,3+0.40$ & $7.5+051 *$ \\
\hline N: Private+/forthright- & $6.6+0.89$ & $2.7+0.6 *$ \\
\hline O: Apprehensive+/self-assured- & $5.6+0.26$ & $3.1+0.40 *$ \\
\hline Q1:Open-to-change +/traditional- & $4,5+0 / 2$ & $7.4+0.60 *$ \\
\hline Q2: self-reliant+/group-oriented- & $6,4+0.45$ & $4.4+0.70$ \\
\hline Q3: Perfectionistic+/tolerates disorder- & $7,4+0.42$ & $4.4+0.33 *$ \\
\hline Q4: Tense+/relaxed- & $5.4+0.41$ & $7.8+0.24 *$ \\
\hline F1: low anxiety+/high anxiety- & $4,5+0 / 2$ & $7.6+0.60 *$ \\
\hline F2: introversion+/extraversion- & $6,4+0.45$ & $3.4+0.70$ \\
\hline F3: Tough-Mindedness+/receptivity- & $4,8+0.42$ & $4.4+0.33$ \\
\hline F4: Independence +/Accommodation- & $5.4+0.41$ & $5.8+0.24$ \\
\hline
\end{tabular}

The comparative analysis of the profiles (we have used Student's t-criterion) has allowed to point out statistically important differences in the scales: C (p $\leq 0.05) ; \mathrm{G}(\mathrm{p} \leq 001) ; \mathrm{M}(\mathrm{p} \leq 0.05) ; \mathrm{N}(\mathrm{p} \leq 0.05) ; \mathrm{Q}(\mathrm{p} \leq 0.05) ; \mathrm{Q} 1$ $(\mathrm{p} \leq 0.05) ; \mathrm{Q} 3(\mathrm{p} \leq 0.05) ; \mathrm{Q} 4(\mathrm{p} \leq 0.05) ; \mathrm{F} 1(\mathrm{p} \leq 0.01)$. 
The analysis of the profile relief allows concluding that for the students with high indices of adaptedness the most prominent traits of character are: discipline, aspiration for order, responsibility, emotional maturity and stability, high level of the behaviour control, good self-organization, developed planning skills, self-sufficiency, adaptedness. In the group with the low indices of the adaptedness the following personality features are sharp: emotionalism, low responsibility, proneness to expressed dreaminess, superfluous straight forwardness, rigidity, impulsiveness, tension, anxiety.

Let us examine the profiles of the personality's viability compiled on the basis of the survey according to the Leontiev and Rasskazova "Viability test table 2".

Table 2 Profiles of the viability indices in groups with different indices of the adaptedness

\begin{tabular}{|l|c|c|}
\hline $\begin{array}{l}\text { Constituents of the of the personal } \\
\text { potential (technique by Leontiev and } \\
\text { Rasskazova "Viability test) }\end{array}$ & \multicolumn{2}{|l|}{ Mean profile in groups } \\
\cline { 2 - 3 } & $\begin{array}{l}\text { With high adaptedness } \\
\text { indices }\end{array}$ & $\begin{array}{l}\text { With low adaptedness } \\
\text { indices }\end{array}$ \\
\hline $\begin{array}{l}\text { viability (integral characteristic, mean } \\
\text { value - 80.72+-18.53) }\end{array}$ & $113.7+10.65$ & $73,2 \pm 11.7$ \\
\hline $\begin{array}{l}\text { involvement (mean value - 37.64+- } \\
8.08)\end{array}$ & $64.2 \pm 5.90$ & $32,2 \pm 6,53$ \\
\hline control (mean value - 29.17+-8.43 & $37,1 \pm 3.70$ & $20.5 \pm 0,31$ \\
\hline $\begin{array}{l}\text { risk acceptance (mean value - 13.91+- } \\
4.39)\end{array}$ & $12,4 \pm 2.50$ & $20.5 \pm 4.24$ \\
\hline
\end{tabular}

The comparative analysis of the profiles in the polar groups allowed to display statistically significant differences between all the indices of the viability and point out the following peculiarities. The adaptants with the high indices of the adaptedness had high indices according to two components forming viability "involvement" and "control", and according to the component "risk acceptance" data are in line with the mean value. Basing on the Leontiev's concept and we can conclude that young specialists of the given group have the conviction that involvement in the professional activities gives them maximum chance in realization of their professional interests and receiving pleasure from their activities. High indices according to the component "control" gives evidence that the formation with a person of a belief that high person's commitment "...allows to influence the result of the events even if the influence is non-absolute and the success is not granted... A person with a developed control feels that he/she chooses his/her personal activity, own way" (Leontiev \& Rasskazova, 2006, p. 5) 
Liubov Kotlyarova, Ekaterina Sysoeva. Influence of the Personal Potential on Adaptation of Young Engineers in the Sphere of the Industrial Production

For those with the low indices of the adaptedness we can observe lowering of the indices on the components "involvement", "control" but according to the component "risk acceptance" - increase of the indices to the mean value. Basing on the results, we can conclude that young specialists with low adaptedness have feeling of rejection, being "out of the life" and self-helplessness, inclination to risk, they see life as a way of acquiring experience, are ready to act without reliable success guarantees.

Summarizing the data we can conclude that the higher the level of the adaptedness is, the higher is the level of the viability and self-regulation and vice versa.

According to the results of the inventory by Maklakov and Chermyanin MLPI-A we have compiled profiles of the adaptation potential in every group formed according to the intensity of the factor "adaptedness" (table 3).

Table 3 Profiles of the personality's adaptation potential in groups with different indices of adaptedness intensity (compilation of the results according to the inventory by Maklakov and Chermyanin "MLPI-A")

\begin{tabular}{|c|c|c|}
\hline \multirow{2}{*}{$\begin{array}{l}\text { The constituents of the personal } \\
\text { adaptation potential (based on the } \\
\text { inventory Maklakov and Chermyanin } \\
\text { "MLPI-A") }\end{array}$} & \multicolumn{2}{|c|}{ Mean profile in the groups: } \\
\hline & $\begin{array}{l}\text { With high adaptation } \\
\text { indices }\end{array}$ & Low indices adaptation \\
\hline Adaptation Abilities “AA" 152 & $139,3 \pm 15.7^{* *}$ & $108.3+10.65$ \\
\hline $\begin{array}{l}\text { Neuro-Psychological Stability "NPS" } \\
96\end{array}$ & $88,1 \pm 6,53$ & $64.1 \pm 5.90$ \\
\hline Communicative Peculiarities "CP" 32 & $27,1 \pm 3.70$ & $19.4 \pm 0,31$ \\
\hline Moral Standartization "MS" 24 & $21,4 \pm 2.50$ & $20.5 \pm 0.24$ \\
\hline Authenticity "A" 13 & $2,7 \pm 0.40$ & $4.3+1.23$ \\
\hline
\end{tabular}

The examination of the personal adaptation profiles shows that significant differences are found according to the scales: adaptation abilities, NPS and CP.

Let us examine the data received as a result of the testing on the inventory by Rostovsky - "Adaptation Potential". According to the results of the survey in every of the selected groups (conventional name of the first group - "high adaptive", second - "low adaptive") we have compiled the profiles of personality's adaptation potential.

In the first group all the indices according to all the constituents of the personality's adaptation correlated with high indices. In the profile of the adaptation potential the leading were the scales reflecting the intensity of adaptation: to the inner "I" image, to the relationships with the students; to the studies; to the attitude to life; to the outer "I" image; to the safety. 
In the group with the low adaptation indices we have revealed the tendency to the decrease of the indices on all the factors of the adaptation potential. The lowest rates were found with the factors: adaptation to the inner "I" image, adaptation to information streams, working schedule adaptation and energetic expenses, time adaptation; adaptation in the system of the inter-personal relationships with the group-mates and communication with the teachers.

Now we will examine the results received according to the survey based on the Rostovsky inventory "Mechanisms of Adaptation". The respondents of the first group ("highly adaptive") as the most prominent have such behavioural strategies as: rationalization, accumulation of the potential, approaching, overcompensation, and weakly manifested are the strategies: self-destruction, leaving for the unreal world, rejection.

In the second group (with the low indices on the "adaptation" factor) in the structure of the behavioural structures prevailed: complication, forming of barriers, self-destruction, rejection. The respondents of the given group seldom resort to usage of such constructive behavioural strategies as - addressing for help to the group, saving of the personal resources, rationalization.

\section{Conclusions}

Summarizing the results of the research we can conclude that personality's potential formed by the graduation from the university among the students of a technical university influences the peculiarities of the adaptation process and the effectiveness of the professional adaptation at the first job placement.

The most prepared are the graduates of the technical university with the developed personal potential. They have quickly adapted to the activities and organizational conditions of an industrial plant. When they were interviewed at the end of the first working year, they have underlined their high satisfaction with their organizational status, activities and relationships. As a factor influencing the effective adaptation, the subjects of the given group singled out: developed personal resources and good organizational conditions. To effective adaptation of the young specialists from this group contributed such personal features as: self-discipline, aspiration for order, responsibility, emotional maturity and stability, high behavioural self-control, good self-organization, developed planning skills and abilities, self-sufficiency, adaptedness. Other things that contributed to the high adaptedness were: constructive behavioural strategies (addressing to the group for help, aspiration for rationalization and potential accumulation) and conviction about the fact that the way chosen by them and high involvement in the professional activities give maximum chance of realization of their professional interests and having satisfaction with work. 
Liubov Kotlyarova, Ekaterina Sysoeva. Influence of the Personal Potential on Adaptation of Young Engineers in the Sphere of the Industrial Production

Young specialists with low adaptation potential could hardly adapt to the contents of the activities, organizational conditions, working schedule, communications, and this led to a decision on resignation. The reasons for resignation according to the respondents were personal and organizational factors such as: discrepancy between the imagined character of work and the real situation: tough working schedule; dissatisfaction with the organization of the working area; dissatisfaction with the system of communication in general; not enough attention from chief to young specialists' demands and requirements. As the factors contributing to deadaptation we must accept the following peculiarities of the personal potential: characteorological - impulsiveness, tension, anxiety, rigidity; emotional - increased emotionality, experiencing the feeling of outcast and self-helplessness, feeling "out of the life", inclination to risk; the behavioural strategies - complication, forming of barriers, selfdestruction, rejection.

Taking into account the fact that one of the reasons for resignation were the organizational ones, we have analyzed the social and HR plants' programmes aimed at young specialists' adaptation and regulatory statutory documentation conditioning personnel management activities in the given direction. Basing on the result of the analysis we have concluded that the programmes on the young specialists' adaptation comply with the managerial and legal criteria. At the same time while studying these programmes in details we learnt that they had been created on the basis of social-economical and organizational-technological approaches, without proposing exact measures aimed at taking into account adaptants' individual-personal.

The given conclusion on the programmes explains why all the respondents have mentioned high satisfaction with the material stimulation. And why they believe that economical factors do not influence course of the adaptation/deadaptation processes.

On the basis of the pointed out patterns we have created recommendations for the university social-psychological services and plants on organization of the psychological accompaniment to the students and young specialist in order to form and improve personal potentia necessary for the effective adaptation and involvement in the professional activities.

\section{References}

Antonov, G. D., Ivanova, O. P., \& Tumin, V. M. (2012). Upravlenie konkurentosposobnosty $u$ predpriyatiya [Management of the Organization Competitiveness]. M.: INFRA-M.

Armstrong, M. (2010). Praktika upravleniya chelovecheskimi resursami [Human Resources Management Practice]. SPb: Piter.

Jung, C. G. (2003). Obschee opisanie tipov [Types General Description] C. G. Jung. Psychological Types. M.: LLC "Hariest". 
Kochan, T. A., \& Dyer, L. (1993). Managing transformational change: the role of human resource professionals. International Journal of Human Resource Management. 4 (3), 509-590.

Kotlyarova, L. N., \& Zhutikov, M. D. (2013). Innovatsionnye podkhody k kadrovoj politike predpriyatij vysokotekhnologichnogo proizvodstva: osobennosti vzaimodejstviya $s$ obrazovatelnymi uchrezhdeniyami [Innovational Approaches to Personnel Policy of the High-Technology Productions: Peculiarities of the Interaction with the Educational Establishments]. Social Economic and Psychological Problems and Psychological Problems of Management (pp. 267-273). Moscow: MGPPU.

Leonov, N. I. (2013). Metody izucheniya konfliktov i konfliktnogo povedeniya [Methods of Studying Conflicts and Conflict Behaviour]. M.: Non-Governmental Educational Establishment of Higher Professional Education Moscow Psychological-Social University.

Leontiev, D. A., Mandrikova, E. U., \& Osin, E. N. (2007). Opyt strukturnoj diagnostiki lichnostnogo potentsiala [The Experience of the Personal Potential Structural Diagnostics]. Psychological Diagnostics, 1, 8-31.

Leontiev, D. A., \& Rasskazova, E. I. (2006). Test zhiznestojkosti [Viability Test]. M.: Smysl.

Maklakov, A. G. (2008). Professionalnyj psikhologicheskij odbor personala. Teoriya i Praktika [Professional Psychological Selection of Personnel. Theory and Practice]. $\mathrm{SPb} .:$ Piter.

Maklakov, A. G. (2001). Lichnostnyj adaptatsionnyj potentsial: ego mobilizaciya i prognozirovanie $\mathrm{v}$ ekstremalnykh usloviyakh [Personal Adaptation Potential: Its Mobilization and Forecasting in the Extreme Conditions]. Psychological Magazine, 22 (1), 16-24.

Maksimtsev, I. A. (2015). Upravlenie chelovecheskimi resursami. [Human Resource Management]. M.: Publishing House Yurait.

Nalchadzhyan, A. A. (1988). Sotsio-psikhologicheskaya adaptatsiya lichnosti (formy, mekhanismy $i$ strategii) [Socio-psychological adaptation of the person (forms, mechanisms and strategies)]. Yerevan: Publisher of Armenian SSR.

Nikiforov, G. S. (2010). Psikhologicheskoe obespechenie professionalnoi deyatelnosti [Psychological Provision of the Professional Activity]. SPb.: Rech.

Onoshko, E. S., \& Kretsan, Z. V. (2009). Ponyatijnoe yadro teorii adaptatsii: terminologicheskij aspekt [Conceptual Core of the Adaptation Theory: Terminological Aspect]. Kemerovo State University Herald, 1, 87-90.

Raigorodsky, D. Y. (2009). Encyklopedia psikhodiagnostiki. Psikhodiagnostika personala. [Psychodiagnosis Encyclopedia. Personnel Psychodiagnosis]. Samara: Publishing House "Barakh-M".

Rostovsky, V. P., \& Kotlyarova, L. N. (2010). Pedagogika i Psikhologiya [Pedagogics and Psychology]. Ufa: BGPU

Tolochek, V. A. (2015). Stili deyatelnosti: resursnyj podkhod [Styles of Activities: Resource Approach]. M.: Publishing house "RAS Institute of Psychology".

Turovets, O. G., \& Bukhalkov, M. I. (2011). Organizatsiya proizvodstva i upravlenie predpriyatiem [Organization of the Production and the Plant Management]. M.: INFRA-M.

Vorobiev, V. M. (1996). Adaptivnye psikhicheskie protsessy i patologicheskie zaschity psikhiki [Adaptive Psychological Processes and Pathological Protection of Psychic]. (pp. 89-94). Observ. Psychology and psychiatry V. M. Bechterev, 4, 89-94. 